Article

\title{
On the Interaction of Adherent Cells with Thermoresponsive Polymer Coatings
}

Katja Uhlig $^{1, *}$, Hans G. Boerner ${ }^{2, \dagger}$, Erik Wischerhoff ${ }^{3}$, Jean-François Lutz ${ }^{3, \star}$, Magnus S. Jaeger ${ }^{1}$, André Laschewsky ${ }^{3}$ and Claus Duschl ${ }^{1}$

1 Fraunhofer Institute for Biomedical Engineering (IBMT), Potsdam 14476, Germany; E-Mails: magnus.jaeger@ibmt.fraunhofer.de (M.S.J.); claus.duschl@ibmt.fraunhofer.de (C.D.)

2 Max Planck Institute for Colloids and Interfaces, Potsdam 14476, Germany;

E-Mail: boernerh@hu-berlin.de

3 Fraunhofer Institute for Applied Polymer Research (IAP), Potsdam 14476, Germany; E-Mails: erik.wischerhoff@iap.fraunhofer.de (E.W.); jflutz@unistra.fr (J.-F.L.); andre.laschewsky@iap.fraunhofer.de (A.L.)

$\dagger$ Present affiliation: Humboldt University, Berlin 12489, Germany

* Present affiliation: Institute Charles Sadron, Strasbourg 67000, France

* Author to whom correspondence should be addressed; E-Mail: katja.uhlig@ibmt.fraunhofer.de; Tel.: +49-331-58187-310; Fax: +49-331-58187-399.

Received: 2 March 2014; in revised form: 1 April 2014 / Accepted: 4 April 2014 /

Published: 15 April 2014

\begin{abstract}
Thermoresponsive polymer coatings allow the control of adhesion of cells on synthetic substrates. In particular, decreasing the temperature below the lower critical solution temperature (LCST) of the polymer triggers the non-invasive detachment of cells from their cultivation substrate. Widening the range of applications of these coatings in cellular biotechnology requires a better understanding of their interaction with cells. By monitoring the morphological changes of cells during their detachment at various temperatures, we provide evidence that cell detachment is an active process. Analyses of cell residues that are left behind by the cells on the substrate during their detachment, further support this notion. In the second part of this work, we show that the kinetics of adhesion and the efficiency of detachment of cells can be controlled through the coadsorption of molecules bearing the peptide motif RGD (arginine-glycine-aspartic acid) with the polymers.
\end{abstract}


Keywords: thermoresponsive polymer; RGD; cell detachment; polyethylene glycol

\section{Introduction}

Control over the interaction of cells with their cultivation substrates is an essential issue whenever in vitro cell model systems are to be established. Cell cultivation substrates coated with thermoresponsive polymers have become popular for providing versatile solutions to this problem. These polymers show a transition at a lower critical solution temperature (LCST): above the LCST, they facilitate cell adhesion, while below the LCST, cells cannot adhere [1-6]. This functional feature can be exploited for the non-invasive recovery of adherent cells from their substrates for further processing and analysis. A wide variety of polymer systems have been described so far which show impressive levels of functionality and efficacy for the gentle detachment of various cell lines [7,8]. However, due to the wide variability of the adhesiveness of cells, there are important cell types that are still difficult to process with conventional thermoresponsive polymer coatings. Cell-specific optimization of the coatings is hampered by an incomplete knowledge of the mechanisms responsible for the cellular response and by limitations of standard protocols for their fabrication.

We employ a thermoresponsive polymer consisting of polyethylene glycol (PEG). This polymer type is well known for its biocompatibility, as well as for its protein repellence and cell repellence [9]. Here, we use a PEG-based thermoresponsive polymer with an LCST of $35^{\circ} \mathrm{C}$. In the first part, we provide evidence that the cell rounding upon a decrease of the cultivation temperature below the LCST is an active physiological process. In this respect, we monitor the behavior of adherent cells after the temperature was decreased to different values below the LCST using total internal reflection fluorescence (TIRF) microscopy. We investigate the material left behind on the coating by cells during detachment from the surface. In the second part, we present results showing that the overall adhesion properties of the coatings can be adjusted through the addition of RGD (arginine-glycine-aspartic acid)-bearing peptides: This motif is present in the extracellular matrix (ECM). The RGD sequence is specifically recognized by integrins, i.e., membrane proteins crucial in mediating cell adhesion [10,11]. Furthermore, it has been shown that molecules bearing RGD groups immobilized on synthetic substrates, including thermoresponsive polymers, enhance cell adhesion [12-14]. However, control over the accessibility of these groups to cells and the functional decoupling of the groups from the polymer is difficult to achieve with "grafting from" standard methods used for the fabrication of polymer layers in most cases. Here, we make use of an approach to form thermoresponsive polymer coatings from poly( $\mathrm{MEO}_{2} \mathrm{MA}$-co-OEGMA) synthesized using 2-(2-methoxyethoxy) ethyl methacrylate ( $\left.\mathrm{MEO}_{2} \mathrm{MA}\right)$ and oligo(ethylene glycol) methacrylate (OEGMA) [15,16]. It is based on the formation of self-assembled monolayers driven by the reactivity of sulfur groups towards gold leading to a surface coverage of 0.2 molecules $\mathrm{nm}^{-2}$ as has been previously determined for pure copolymer layers [15]. We employ mixtures of RGD-bearing molecules and thermoresponsive polymers which are equipped with cysteine and disulfide groups, respectively (see Scheme 1). As each molecule is individually anchored to the surface and the length of the spacer of the RGD-bearing molecules is varied, the accessibility of this peptide to the cells and the interaction between the different functional moieties in the layer can be 
closely controlled. In this work, we form layers containing RGD-bearing molecules with three different spacer lengths that are mixed with the polymer at various ratios. For evaluating the layers, we use L929 mouse fibroblasts (ACC 2, DSMZ, Braunschweig, Germany). These cells rarely develop cell-cell contacts and, hence, their morphological changes and detachment upon a temperature change is primarily dominated by their interaction with the substrate.

Scheme 1. The scheme shows the structures of the molecules employed and the concept of mixed films: (a) the thermoresponsive polymer poly( $\left.\mathrm{MEO}_{2} \mathrm{MA}-\mathrm{co}-\mathrm{OEGMA}\right)$ and molecules with a RGD motive; (b) a pure peptide sequence CGGRGDS; (c) a peptide sequence with an inserted oligo ethylene glycol (C(OEG) $)_{3}$ GRGDS); or (d) an OEGMA-RGD.
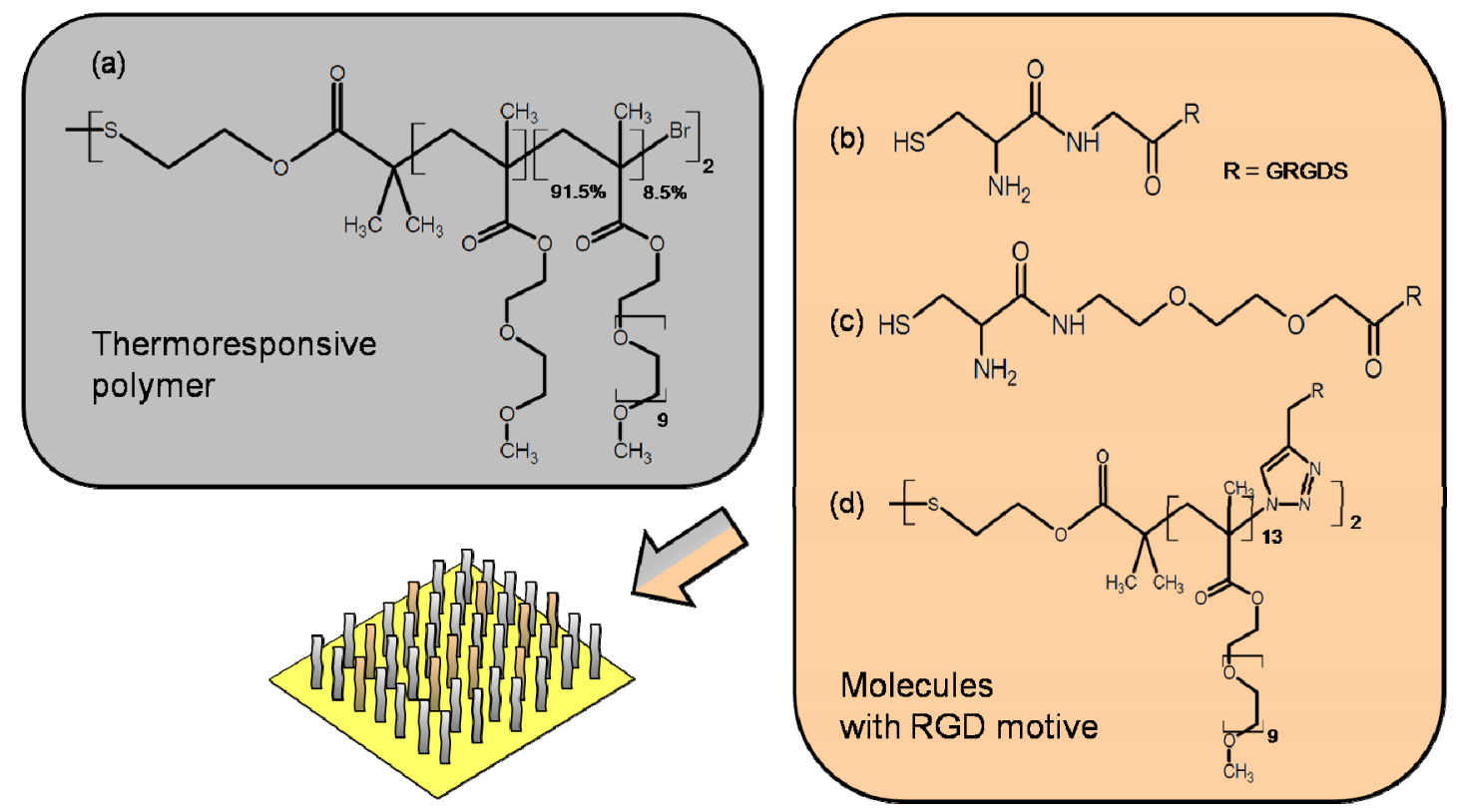

\section{Experimental Section}

\subsection{Polymer Synthesis}

The methacrylate derivative-based thermoresponsive polymers and the methacrylate derivative-based spacer poly(OEGMA) were synthesized by atom transfer radical polymerization (ATRP) analogous to [17] starting from an initiator incorporating a disulfide bond (ATRP) [18]. The thermoresponsive polymer poly $\left(\mathrm{MEO}_{2} \mathrm{MA}-\mathrm{co}\right.$-OEGMA $)\left(M_{\mathrm{W}}=25 \mathrm{~kg} \cdot \mathrm{mol}^{-1}\right)$ has been described in detail in a previous report [15].

\subsection{Peptide Synthesis}

$N$ - $\alpha$-Fmoc-protected amino acids (Fmoc-Gly-OH, Fmoc-L-Arg(Pbf)-OH, Fmoc-L-Cys(Trt)-OH, Fmoc-L-Asp(tBu)-OH), 2-Fmoc-(2-aminoethoxy)ethoxyacetic acid (miniPEO), 2-(1H-benzotriazole-1yl)-1,1,3,3-tertamethyluroniumhexafluorophosphate (HBTU) and 2-chlortrityl poly(styrene)resin (preloaded with Ser(tBu) with a loading of $0.61 \mathrm{mmol} \cdot \mathrm{g}^{-1}$ ) were used as received from IRIS Biotech (Marktredwitz, Germany). 4-pentynoic acid (PA) was used as received from Sigma Aldrich (Steinheim, Germany). Fmoc-L-Ser(tBu)-OH and (benzotriazol-1-yloxyl) tripyrrolidino-phosphonium- 
hexafluorophosphate (PyBOP) were used as received from Novabiochem, Merck (Darmstadt, Germany). Piperidine (99\%, Alfa Aesar, Karlsruhe, Germany) and diisopropylethylamine (DIPEA; 99.96\%, IRIS Biotech), were distilled from $\mathrm{KOH}$ prior to use. Triethylsilane (TES, 98+\%, Alfa Aesar) has been used as received. $N$-methyl-2-pyrrolidone (NMP, 99.9+\%, peptide synthesis grade, IRIS Biotech) was purified by filtration through a column $(10 \mathrm{~cm} \times 60 \mathrm{~cm})$ filled with aluminum oxide and silica gel at a rate of $1 \mathrm{~mL} \cdot \mathrm{min}^{-1}$. Trifluoracetic acid (TFA; IRIS Biotech, peptide grade) was distilled prior to use. Dichloromethane (DCM, IRIS Biotech, peptide grade) was distilled from $\mathrm{CaH}_{2}$ prior to use.

The peptide synthesis was performed on an Applied Biosystems ABI 433a peptide synthesizer on a $0.1 \mathrm{mmol}$ scale, using a Ser-preloaded 2Cl-Trt PS resin as solid support. Fmoc amino acid derivatives were coupled following standard ABI-FastMoc protocols (single coupling, no capping) in NMP, facilitated by HBTU/DIPEA (HBTU: 0.95 equivalent with respect to amino acid; DIPEA: 2 equivalent with respect to amino acid). In case of $N$-terminal modification (PA or Cys-miniPEO), the resin was transferred to a $40 \mathrm{~mL}$ glass reactor after final Fmoc removal. 4-pentynoic acid (PA) was double-coupled at ambient temperature and after each coupling step the resin was washed with NMP; 1st coupling: 1.0 mmol PA, 1.0 mmol PyBoP, 2.0 mmol DIPEA for $1 \mathrm{~h}$; 2nd coupling: 0.5 mmol PA, $0.5 \mathrm{mmol}$ PyBoP, 1.0 mmol DIPEA for 12 h. 2-Fmoc-(2-aminoethoxy)ethoxyaceticacid(miniPeo) was three times single-coupled for $1.5 \mathrm{~h}$; coupling conditions: $0.4 \mathrm{mmol}$ miniPEO, $0.4 \mathrm{mmol}$ PyBoP, $0.8 \mathrm{mmol}$ DIPEA. The full conversion was confirmed by a negative Kaiser test. In case of a positive test, the coupling time was extended overnight (2nd and 3rd couplings). After each coupling step, the resin was washed with NMP and the Fmoc protective groups were cleaved with $20 \%$ piperidine/NMP for $30 \mathrm{~min}$. The terminal Cys was coupled fully automated following standard ABI-FastMoc protocols.

Finally, the supports were washed three times with NMP and dichloromethane (DCM) and dried overnight under vacuum at $25{ }^{\circ} \mathrm{C}$. The peptides were liberated from the resin by treatment with trifluoroacetic acid (TFA)/water/triethylsilane(TES) 95:3:2 v/v\% for $2 \mathrm{~h}$ to obtain the completely deprotected peptide. The peptides were isolated by diethylether precipitation, reprecipitation from TFA, centrifugation and single lyophilization from water/acetonitrile. The chemical identities of the products were confirmed by ESI-MS analysis: RGD: sequence: CGGRGDS, mass signal at m/z 651 assignable to $[\mathrm{M}+\mathrm{H}]+$ with $0.1 \mathrm{Da}$ accuracy (Mth, CGGRGDS = $650 \mathrm{Da}$ ); RDG: sequence: CGGRDGS, mass signal at $\mathrm{m} / \mathrm{z} 651$ assignable to $[\mathrm{M}+\mathrm{H}]+$ with $0.1 \mathrm{Da}$ accuracy $(\mathrm{Mth}$, CGGRDGS $=650 \mathrm{Da}$ ); OEG-RGD: sequence: C-(miniPeo) ${ }_{3}$-GRGDS-COOH, mass signal at m/z 516 and 1030 assignable to $[\mathrm{M}+2 \mathrm{H}] 2+$ and $[\mathrm{M}+\mathrm{H}]+$, respectively, with $0.1 \mathrm{Da}$ accuracy (Mth, C-(Peo) $)_{3}$ GRDGS = $1029 \mathrm{Da}$ ); OEGMA-RGD: The (OEGMA) 13 was functionalized using the 1,3-dipolar cycloaddition [19] for the linkage of the peptide with the sequence PA-GRGDS-COOH, mass signal at $\mathrm{m} / \mathrm{z} 571$ assignable to $[\mathrm{M}+\mathrm{H}]+(\mathrm{Mth}, \mathrm{PA}-\mathrm{GGRDGS}=570.4 \mathrm{Da})$.

\subsection{Surface Modification}

The thermoresponsive polymers and RGD peptides were immobilized by chemisorption to gold surfaces through covalent binding of a central disulfide group or the thiol group of the terminal cysteine respectively. For this purpose, glass cover slips $(20 \mathrm{~mm} \times 20 \mathrm{~mm}$, Menzel, Braunschweig, Germany) were first coated with chromium $(2 \mathrm{~nm})$ and gold $(47 \mathrm{~nm})$ using an Auto 500 Electron Beam Evaporation System (Edwards, Clawley, UK). Directly after evaporation, the gold substrates were 
immersed into an aqueous solution containing different ratios of stock solutions of disulfidepoly( $\left.\mathrm{MEO}_{2} \mathrm{MA}-\mathrm{co}-\mathrm{OEGMA}\right)$ and RGD peptides for $3 \mathrm{~h}$ at room temperature without shaking. The concentration of the RGD peptide stock solutions (RGD, RDG and OEG-RGD) was $50 \mu \mathrm{M}$. Due to the centrally located disulfide of the poly( $\mathrm{MEO}_{2} \mathrm{MA}-\mathrm{co}$-OEGMA) and the OEGMA-RGD molecules, two immobilized polymer chains result from one molecule after immobilization. Therefore, concentrations of $25 \mu \mathrm{M}$ were used. Unbound polymer was removed by repeated washing of the gold substrate in water for $1 \mathrm{~h}$. Finally, the slides were dried with nitrogen and immediately used for cell cultivation.

\subsection{Cell Experiments}

L929 mouse fibroblasts (ACC 2, DSMZ, Braunschweig, Germany) were cultivated in DMEM containing $25 \mathrm{mM}$ HEPES, 10\% FCS (fetal calf serum), 1\% penicillin/streptomycin and $2 \mathrm{mM}$ L-glutamine (all Biochrom, Berlin, Germany) at $37{ }^{\circ} \mathrm{C}$ and $5 \% \mathrm{CO}_{2} \cdot 10^{4}$ cells $\cdot \mathrm{cm}^{-2}$ were seeded on freshly prepared thermoresponsive poly( $\mathrm{MEO}_{2} \mathrm{MA}-\mathrm{co}$-OEGMA) and RGD peptide surfaces and stored in an incubator. For measuring the cell spreading time, the samples were examined for less than $1 \mathrm{~min}$ outside the incubator after 3, 24, 48 and $72 \mathrm{~h}$. The cell spreading time is defined as the time it takes $50 \%$ of the cell population to form pseudopodia on the surface. After this time, the substrates were cooled down to room temperature $\left(\sim 22^{\circ} \mathrm{C}\right)$, i.e., below the polymer's LCST. Assessing both spreading time and rounding efficiency (explained below) requires observation of the cells' morphology. To this end, the samples were quickly transferred from the incubator to an optical microscope at room temperature equipped with a $10 \times / 0.25$ objective and a Nikon Digital Sight DS-L1 (all Nikon, Duesseldorf, Germany). The rounding efficiency is the percentage of cells that change from the spread to the spherical state. Due to the long time that cells need to adhere on the thermoresponsive surfaces, the medium had to be supplemented with fetal calf serum (FCS). This poorly defined protein cocktail also contains components that are involved in the RGD-mediated adhesion.

TIRF microscopy was performed using an inverted microscope (IX 71) equipped with a TIRF condenser (Olympus, Hamburg, Germany), a 60×/1.45 oil immersion objective, a cooled CCD (charge-coupled device) camera (F-View) and software (CellF, all Olympus, Hamburg, Germany). To visualize the cell adhesion area, a polar dye (Alex Fluor 568 hydrazide, sodium salt, Life Technologies, Eugene, OR, USA) was added to the aqueous media at a concentration of $25 \mu \mathrm{g} \cdot \mathrm{mL}^{-1}$ before imaging. Fluorescence was excited with an $\mathrm{Ar} / \mathrm{Kr}$ laser (Omnichrome, Melles Griot Laser Group Carlsbad, Albuquerque, NM, USA). Details about TIRF microscopy of thermoresponsive polymer surfaces are found in [16].

\section{Results and Discussion}

In the following, we describe experiments that were designed for better understanding which factors contribute to the response of cells on a thermoresponsive surface when the temperature decreases below the LCST. The data in Figure 1 show the percentage of cells that assume a spherical morphology upon a temperature decrease below the LCST after having been spread on a thermoresponsive substrate at $37^{\circ} \mathrm{C}$ for three days. The kinetics of morphological changes of the cells was recorded after the temperature was decreased from $37{ }^{\circ} \mathrm{C}$ to $22^{\circ} \mathrm{C}$, to $15^{\circ} \mathrm{C}$ and to $4{ }^{\circ} \mathrm{C}$. The data show that the kinetics of cell rounding was slowest at $4{ }^{\circ} \mathrm{C}$. At $15{ }^{\circ} \mathrm{C}$ and at $22{ }^{\circ} \mathrm{C}$, this process 
occurred at similar rates. These data prompt the question of which elements of this processes are sensitive to temperature changes within this range. Besides the structural change of the thermoresponsive polymer, this is the metabolism of the cells. The latter eventually controls the rate at which morphological changes can occur. As the structural change of the only a few nanometers thick polymer layer occurs considerably faster than the observed cell rounding, it is reasonable to assume that the rounding is an active process of the cells and that the kinetics of the transition of the polymer at the LCST does not play a major role. Moreover, this argument is in line with results obtained by colloidal probe measurements which suggest that the kinetics of the change of cell morphology upon the decrease of temperature is determined by cellular processes rather than by the dynamics of the transition of the polymers [20]. The assumption of an actively driven cell detachment on thermoresponsive surfaces is further supported by observations of Okano et al. [21] on poly( $N$-isopropylacrylamide)-coatings who also described a reduced cell detachment efficiency at lower temperatures and after chemical manipulation of the cell metabolism $[22,23]$.

Figure 1. The graph shows cell rounding kinetics of L929 mouse fibroblasts on thermoresponsive substrates at $22^{\circ} \mathrm{C}$ (black circles), $15^{\circ} \mathrm{C}$ (gray circles), and $4{ }^{\circ} \mathrm{C}$ (open circles). The slow kinetics of cell rounding at $4{ }^{\circ} \mathrm{C}$ is indicative of an active cell response.

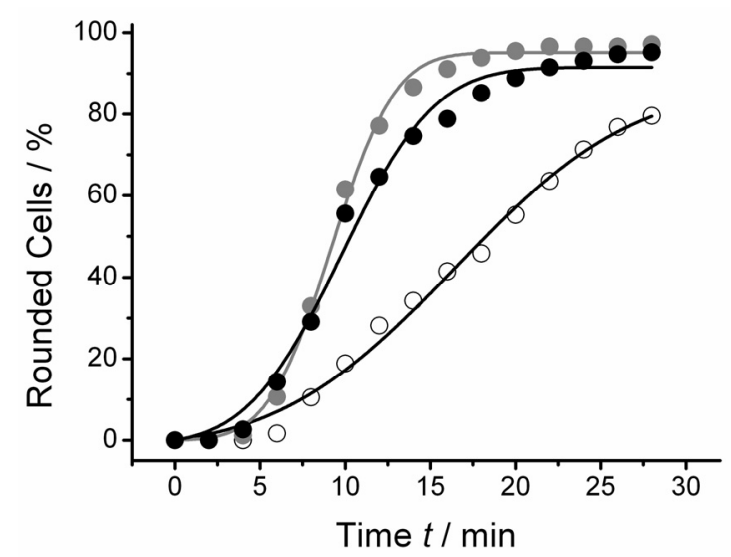

A phenomenon frequently observed when the migration or rounding of adherent cells on synthetic surfaces is monitored is that the cells leave residues behind on the surface from where they detach. The occurrence of these structures has previously been reported for non-stimuli responsive surfaces [24,25]. Their detailed analysis reveals tubular aggregates containing lipids of the cell membrane and proteins of the membrane and the cytosol. Varyingly termed cell traces or biotubes, these deposits may be related to tubular structures that have been observed to guide material transport between cells. The sequence of micrographs in Figure 2 shows the representative behavior of an adhering L929 mouse fibroblast on a thermoresponsive substrate over time upon a temperature decrease from 37 to $25{ }^{\circ} \mathrm{C}$ (at the start of the sequence). The sequence corresponds to a period of $60 \mathrm{~min}$ and was taken using TIRF microscopy. The key element of this method is an evanescent field that restricts the excitation of fluorescence to the surface of the substrate. The different access of a polar soluble fluorophores to this field produces the contrast, since regions where cells or cell traces adhere are inaccessible to the dye molecule and consequently appear dark. Bright areas, in contrast, represent regions of open surface where the fluorophores diffuse into the evanescent light sheet. The first three images exhibit a fast 
reduction of the contact area of the cell. Previous studies showed that this reduction corresponded to a change of morphology of the cell from a spread to a spherical shape [16]. In the third image, the cell has migrated to the right leaving a clearly visible network of traces behind. The structural features of this network resemble those of the adhesion pattern. The latter is highly dynamic, also during the migration of the cell. The fact that these traces are clearly visible suggests that their thickness must be at least in the range of the depth of the evanescent field which is approximately $120 \mathrm{~nm}$. The traces occurred only in the area where the cell was located immediately before lowering of the temperature. There was no indication of cell residues generated during migration, neither at 37 nor at $22{ }^{\circ} \mathrm{C}$. Interestingly, the deposited network shows activity resulting in a considerable reorganisation of the cell traces (see insert in Figure 2), although no direct connection between the cell and the traces is visible in the TIRF microscopy mode. This rearrangement not only concerns the finely extended deposits but also the more obvious spots appear, disappear and reappear again. The dynamic behavior can be explained by assuming that there is a reorganisation of components of the cytoskeleton and/or remaining activity of motor proteins associated with the cytoskeleton. Because of the morphological changes, we believe that primarily motor proteins are responsible for this behavior. Motor proteins require ATP to be active. Hence, we suppose that the traces store residual ATP over time scales of several tens of minutes. These results are in agreement with a model of these traces according to which they consist of tubules of a diameter of approximately $100 \mathrm{~nm}$ formed by lipid bilayers [24]. Besides the presence of actin in these tubes, several membrane proteins, such as $\beta 1$ integrin, the transferrin receptor and the major histocompatibility complex (MHC) were detected in them [24].

Figure 2. Time series of a total internal reflection fluorescence (TIRF) microscopy images (contrast enhanced) at different times during cell detachment (L929 mouse fibroblast) upon cooling a thermoresponsive substrate. The fibroblast left cell material on the substrate. The cell traces were rearranging themselves throughout the observation time of $60 \mathrm{~min}$ (compare inserts taken at 44 and $45 \mathrm{~min}$, and at 50 and $51 \mathrm{~min}$ ).

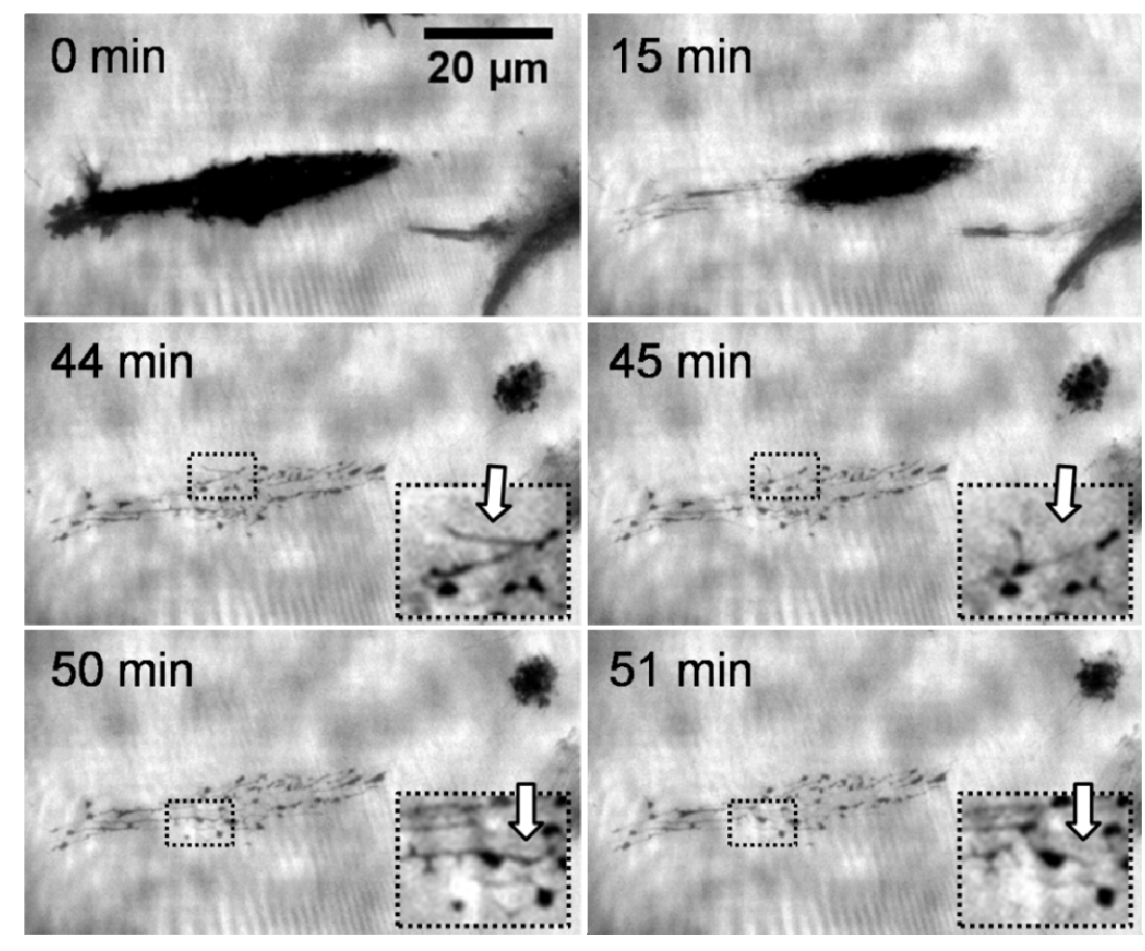


The fact that cells leave material behind when they detach from the thermoresponsive coatings at the LCST further strengthens the notion that this detachment is an active process. This behavior would be difficult to reconcile with the assumption of a purely physiochemical process in which the adhesion energy between the cell and the thermoresponsive substrate is simply reduced when the temperature drops below the LCST. The remaining cell traces can also not be explained by locally enhanced adhesion resulting from ECM proteins secreted during cultivation. Two of our observations argue against this: Firstly, the adhesion pattern of the cells was highly dynamic and the distribution of the focal adhesion contacts constantly changing. As a consequence, the deposition of ECM material should be rather homogeneous. Secondly, as the constant rearrangement of the traces shows (arrows in the inserts of Figure 2), they do not adhere strongly to the substrate. In summary, the transition of the thermoresponsive polymers at the LCST apparently induces an active response of the adhering cells. We could not identify the molecular stimulus that the cells respond to. The intracellular pathways also remain to be elucidated. Besides the relevance of cell traces for a better understanding of the fundamental interaction between cells and polymer coatings, they may also have an important practical benefit for analyzing the molecular composition of the cell membrane [24]. Such an analysis could be non-invasive, using methods like mass spectroscopy, while the cell that generated the traces remains unaffected and viable.

For technological utilizations of the thermoresponsive coatings, a quick adhesion of cells to the substrates is desirable. This is especially relevant to weakly adhering cells on thermoresponsive coatings consisting of poly( $\mathrm{MEO}_{2} \mathrm{MA}-\mathrm{co}$-OEGMA). To this end, we investigated the dependence of the time required for the cell spreading on the coadsorption of molecules that bear a terminal RGD group. Simultaneously, we tested whether the thermal cell detachment property of the polymers was still maintained.

$A b$ initio predicting the accessibility of RGD to the cell's integrin in the presence of the thermoresponsive polymer is impossible, since parameters like the lateral spacing and the surface distance of the RGD motif influences the integrin binding probability. Therefore, we developed three RGD molecules of different chemical structure in order to vary the exposure of the RGD motif on the surface (Scheme 1): (1) a pure peptide sequence CGGRGDS immobilized via the thiol group of cysteine and comprising two glycines (GG) that form a spacer of a length of $0.4 \mathrm{~nm}$ (short: RGD); (2) a peptide sequence with an inserted oligo ethylene glycol ( $(\mathrm{OEG})_{3} \mathrm{GRGDS}$ ) that forms a spacer of a length of $1.8 \mathrm{~nm}$ (short: OEG-RGD); and (3) an OEGMA-RGD with a central disulfide group and with a spacer length of $\sim 4 \mathrm{~nm}$ (short: OEGMA-RGD). Thermoresponsive polymers were mixed at different ratios with these RGD derivatives to obtain surface coatings of varying lateral RGD concentration and RGD exposure. The time needed for the cell spreading was analyzed using L929 mouse fibroblasts. An exemplary cellular behavior on surfaces coated with different concentrations of RGD is shown in Figure 3. 
Figure 3. Phase contrast images of L929 mouse fibroblasts on different thermoresponsive substrates, produced by coadsorption by varying the ratios of poly $\left(\mathrm{MEO}_{2} \mathrm{MA}-\mathrm{co}\right.$-OEGMA) and RGD peptide (percentage, left column). The total concentration of the coating solution was $50 \mu \mathrm{M}$. The time needed for complete cell spreading after seeding, strongly depended on the amount of the peptide. After cell spreading, the samples were exposed to room temperature $\left(\sim 22^{\circ} \mathrm{C}\right)$ for $30 \mathrm{~min}$ (right column). The scale bar is $50 \mu \mathrm{m}$.

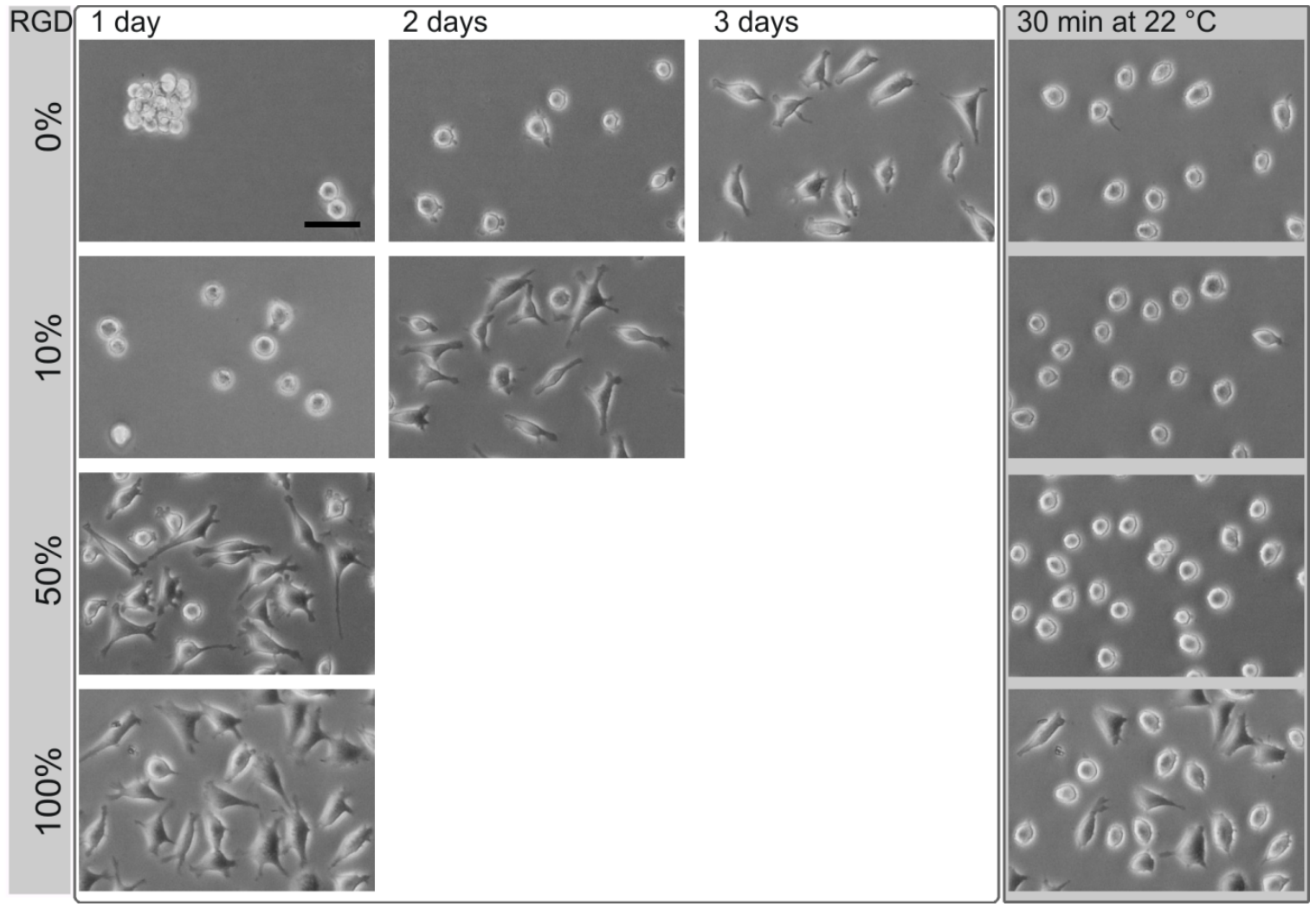

On surfaces coated with poly( $\mathrm{MEO}_{2} \mathrm{MA}-\mathrm{co}$-OEGMA) alone, L929 mouse fibroblasts need three days for spreading (Figure 3, first row). Initially after seeding, the cells are spherical. One day after cultivation, the cells aggregate despite their strong cell-cell contact avoidance observed under control conditions. After two days of cultivation, these aggregates disperse into individual cells, a minority of which develops pseudopodia. Three days after cultivation, the majority of cells is spread. In this state, the thermoresponsive substrate was cooled down to $22{ }^{\circ} \mathrm{C}$. As a result, the cells change from a flat, spread shape to an elevated, round shape within $30 \mathrm{~min}$. In this, they can easily be flushed away from the surface [15]. The cell spreading was accelerated by employing surfaces coated with mixtures of RGD peptides containing poly( $\mathrm{MEO}_{2} \mathrm{MA}-\mathrm{co}$-OEGMA). With an increasing proportion of the peptide, the cell spreading time decreased: Using a coating solution with a molar ratio of $10 \%$ RGD and $90 \%$ poly( $\mathrm{MEO}_{2} \mathrm{MA}-\mathrm{co}$-OEGMA) reduced the cell spreading time to about two days. For coatings with $50 \%$ RGD, the spreading time shortened to one day. This change in composition altered neither the cell rounding nor the cell detachment after the substrates had been cooled down below the LCST (Figure 3, right column). The results for the cell spreading time on surfaces generated by different ratios of thermoresponsive polymer and RGD peptide $(\boldsymbol{\Delta})$, OEG-RGD (•) and OEGMA-RGD ( $\square$ ) are shown in Figure 4A. 
Figure 4. (A) Cell spreading time and (B) rounding efficiency of L929 mouse fibroblasts on different thermoresponsive substrates, produced by coadsorption of poly $\left(\mathrm{MEO}_{2} \mathrm{MA}-\mathrm{co}-\right.$ OEGMA) and varying ratios (abscissa) of RGD peptides: RGD with a short spacer of $0.4 \mathrm{~nm}$ (black triangles), OEG-RGD with an intermediate spacer of $1.8 \mathrm{~nm}$ (gray circles) and OEGMA-RGD with a long spacer of $4 \mathrm{~nm}$ (open squares). The numbers for the fraction of RGD represent the composition in the solution and not necessarily in the coating.
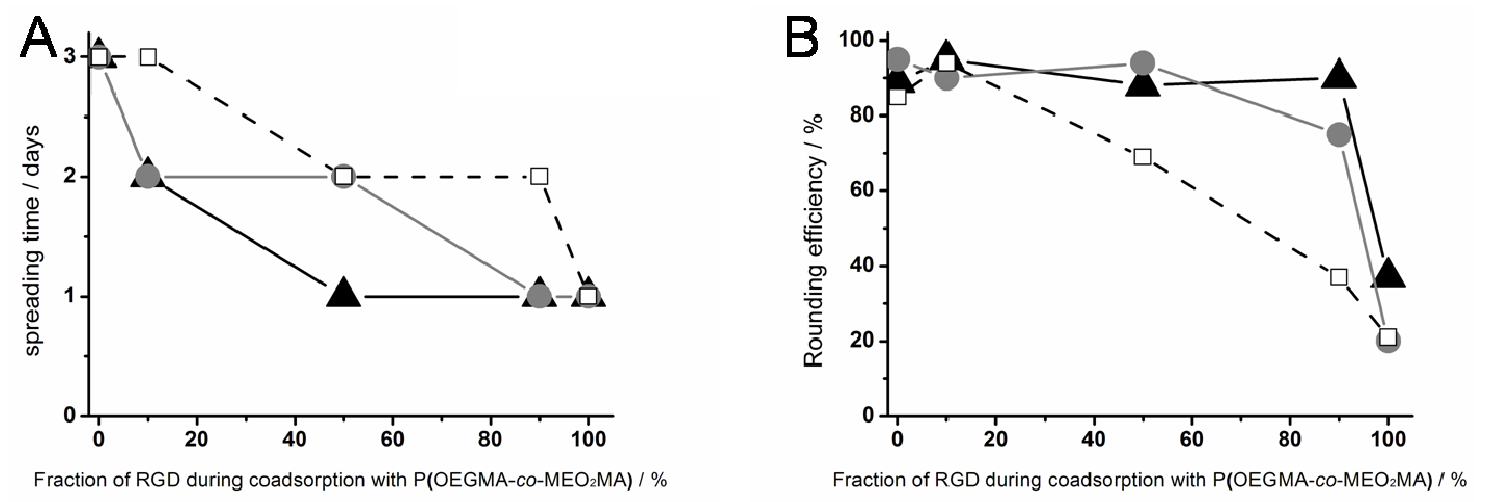

On thermoresponsive surfaces containing OEG-RGD, the spreading occurred at the same rate as on the pure peptide with the exception at a mixing ratio of 50\%: Here, the cell spreading lasted two days. This shows that OEO-RGD molecules are less effective in reducing the cell spreading time than the pure peptides. The cell spreading time measured on coatings containing OEGMA-RGD was two days for each composition tested (except for the $100 \%$ peptide surface).

The cell rounding efficiency after crossing the LCST was affected by the chemical structure of the RGDs as well (Figure 4B): Pure coatings of RGD derivatives, i.e., without thermoresponsive polymer, did not mediate cell rounding $(\sim 20 \%)$ beyond what was observed as non-specific response to the temperature shift employed on other cell culture materials [15]. This suggests that the peptides did not undergo a phase transition in the observed temperature range. The OEGMA-RGD reduced the cell rounding efficiency at and above concentration ratios of $50 \%$ in comparison to pure polymer coatings. The OEGMA is even more space consuming than OEG. Consequently, the distance between the thermoresponsive polymers became too large as compared to surface coatings with the same molar ratios using the smaller peptides, thus resulting in poor cell detachment properties. In contrast, coatings containing 10\% thermoresponsive polymer and 90\% RGD showed a high cell rounding efficiency of $\sim 90 \%$.

The influence of the different chemical properties of the RGD derivatives on the cell behavior was surprising. Our aim had been to improve the accessibility of the RGD motif in the thermoresponsive coating through incorporating an OEG or an OEGMA spacer into the RGD-bearing molecules. Obviously, the introduction of these spacers into such molecules is of limited effect in comparison to the pure peptide. There are several reasons conceivable for the behavior observed: Firstly, the mixing ratios we provide refer to the solution. Molecular properties such as the diffusion constant or the solubility may substantially shift the mixing ratio in the coating relative to that in solution. Secondly, the miscibility of the two molecular components of the coating may vary depending on the type of the spacer. In this case, clusters may form that limit the accessibility of the RGD motif. Finally, 
unfavorable interactions of the cells with the molecular groups that form the spacer may limit the effect of the peptide motif.

Unexpectedly, the short RGD motif mediated the fastest cell spreading on surfaces consisting of thermoresponsive polymer and RDG derivative mixtures. This finding leads to the question whether this was due to a specific receptor ligand interaction. Therefore, the RGD was substituted with RDG, a peptide that does not bind to the cell's integrin. However, when we coadsorbed the RDG peptide, at a molar ratio of $10 \%$ with $90 \%$ thermoresponsive polymer on a surface, the cell spreading time also decreased by one day. This implies that the cells interacted with the surface non-specifically. Possibly, the reduction in the cell spreading time was brought about by the incorporation of charged peptides into the coating-independent of their sequence (RGD or RDG). We verified both peptides' functionality by comparing the cell spreading when either RGD or RDG were added to the medium (Figure 5): The cell spreading time was similar for cells cultivated in RDG-containing medium and in medium without added peptide. In contrast, cell spreading was reduced in cells exposed to RGD-supplemented medium. In the latter case, the cells' integrin receptors were presumably occupied by the dissolved RGD and, therefore, did not contribute to cell adhesion and spreading. While the binding of the RGD peptides to the mouse fibroblast integrins was thus demonstrated, their accessibility appears to be restricted when they are immobilized. Evidently, no specific interaction between surface-bound RGD and the cells' integrin occurred here. A specific integrin-RGD interaction was possibly suppressed by proteins supplemented in the cell medium that screen the RGD moieties, as has been reported for RGD-grafted poly( $N$-isopropylacrylamide)-surfaces [26]. The cell spreading may, thus, be accelerated by omitting serum proteins. This issue will be elucidated in the future by measuring the serum protein adsorption on surfaces modified with poly( $\left.\mathrm{MEO}_{2} \mathrm{MA}-\mathrm{co}-\mathrm{OEGMA}\right)$ or RGD. Nevertheless, embedding peptides between the thermoresponsive polymers improved the cell adhesion non-specifically and markedly reduced the cell spreading time.

Figure 5. The graph shows the spreading kinetics of L929 mouse fibroblasts on glass substrates in various media. Filled black dots indicate pure medium without dissolved peptides, open circles represent medium with $1 \mathrm{mM}$ RGD, while gray dots are obtained from measurements in medium with $1 \mathrm{mM}$ RDG. In the presence of RGD, cell spreading was markedly slower, indicating its interaction with the integrins of cell membrane. In contrast, RDG did not influence cell spreading.

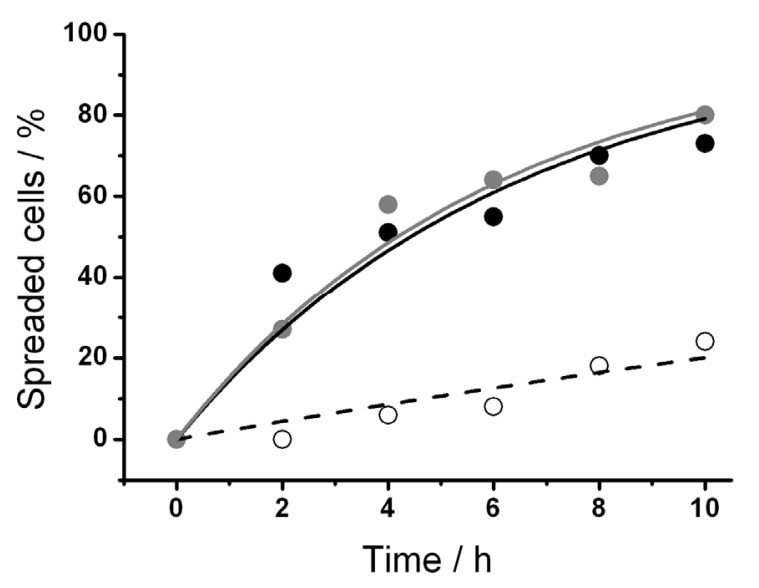




\section{Conclusions}

In this contribution, we provide evidence that cell detachment from a thermoresponsive polymer substrate on a temperature decrease below the LCST of the polymer, is an active process by the cell. Two observations support this statement: Firstly, the kinetics of cell detachment is slower at $4{ }^{\circ} \mathrm{C}$ compared to a faster cell detachment at 15 or $22^{\circ} \mathrm{C}$, most probably because the cell metabolism slows down at lower temperatures. Secondly, the cell material remains on the surface during cell detachment. The cell sacrifices material through actively shedding membrane components including lipids and proteins.

Furthermore, we investigated the impact of RGD peptides mixed into a layer of poly( $\mathrm{MEO}_{2} \mathrm{MA}-\mathrm{co}$ OEGMA) on cell adhesion, using different ratios of thermoresponsive polymer and peptide during coimmobilization. The incorporation of signal peptides accelerated the cell spreading, but this effect appeared to be non-specific, as it was independent of the order of amino acids.

\section{Acknowledgments}

This research was supported through the interdisciplinary network of excellence "Synthetic Bioactive Surfaces" of the Fraunhofer Society and the Max Planck Society.

\section{Author Contributions}

Katja Uhlig performed the experiments. Erik Wischerhoff, Jean-François Lutz and André Laschewsky synthesized the polymers. Magnus S. Jaeger carried out data analysis. Hans G. Boerner synthesized the peptides. Katja Uhlig, Claus Duschl and Magnus S. Jaeger wrote the manuscript.

\section{Conflicts of Interest}

The authors declare no conflict of interest.

\section{References}

1. Yamada, N.; Okano, T.; Sakai, H.; Karikusa, F.; Sawasaki, Y.; Sakurai, Y. Thermo-responsive polymeric surfaces; control of attachment and detachment of cultured cells. Macromol. Chem. Rapid Commun. 1990, 11, 571-576.

2. Schmidt, S.; Zeiser, M.; Hellweg, T.; Duschl, C.; Fery, A.; Möhwald, H. Adhesion and Mechanical Properties of PNIPAM Microgel Films and Their Potential Use as Switchable Cell Culture Substrates. Adv. Funct. Mater. 2010, 20, 3235-3243.

3. Halperin, A.; Kröger, M. Theoretical considerations on mechanisms of harvesting cells cultured on thermoresponsive polymer brushes. Biomaterials 2012, 33, 4975-4987.

4. Halperin, A.; Kröger, M. Thermoresponsive Cell Culture Substrates Based on PNIPAM Brushes Functionalized with Adhesion Peptides: Theoretical Considerations of Mechanism and Design. Langmuir 2012, 28, 16623-16637.

5. Choi, S.; Choi, B.-C.; Xue, C.; Leckband, D. Protein Adsorption Mechanisms Determine the Efficiency of Thermally Controlled Cell Adhesion on Poly( $N$-isopropyl acrylamide) Brushes. Biomacromolecules 2013, 14, 92-100. 
6. Xue, C.; Choi, B.-C.; Choi, S.; Braun, P.V.; Leckband, D.E. Protein Adsorption Modes Determine Reversible Cell Attachment on Poly( $N$-isopropyl acrylamide) Brushes. Adv. Funct. Mater. 2012, 22, 2394-2401.

7. Wischerhoff, E.; Uhlig, K.; Lankenau, A.; Börner, H.G.; Laschewsky, A.; Duschl, C.; Lutz, J.-F. Controlled cell adhesion on PEG-based switchable surfaces. Angew. Chem. Int. Ed. 2008, 47, 5666-5668.

8. Cole, M.A.; Voelcker, N.H.; Thissen, H.; Griesser, H.J. Stimuli-responsive interfaces and systems for the control of protein-surface and cell-surface interactions. Biomaterials 2009, 30, 1827-1850.

9. Gombotz, W.R.; Wang, G.H.; Horbett, T.A.; Hoffman, A.S. Protein adsorption to poly(ethylene oxide) surfaces. J. Biomed. Mater. Res. 1991, 25, 1547-1562.

10. Humphries, M. The molecular basis and specificity of integrin-ligand interactions. J. Cell Sci. 1990, 97, 585-592.

11. Hersel, U.; Dahmen, C.; Kessler, H. RGD modified polymers: biomaterials for stimulated cell adhesion and beyond. Biomaterials 2003, 24, 4385-4415.

12. Hatakeyama, H.; Kikuchi, A.; Yamato, M.; Okano, T. Patterned biofunctional designs of thermoresponsive surfaces for spatiotemporally controlled cell adhesion, growth, and thermally induced detachment. Biomaterials 2007, 28, 3632-3643.

13. Smith, E.; Yang, J.; McGann, L.; Sebald, W.; Uludag, H. RGD-grafted thermoreversible polymers to facilitate attachment of BMP-2 responsive C2C12 cells. Biomaterials 2005, 26, 7329-7338.

14. Farrugia, B.L.; Kempe, K.; Schubert, U.S.; Hoogenboom, R.; Dargaville, T.R. Poly(2-oxazoline) Hydrogels for Controlled Fibroblast Attachment. Biomacromolecules 2013, 14, 2724-2732.

15. Uhlig, K.; Boysen, B.; Lankenau, A.; Jeager, M.; Wischerhoff, E.; Lutz, J.-F.; Laschewsky, A.; Duschl, C. On the influence of the architecture of poly(ethylene glycol)-based thermoresponsive polymers on cell adhesion. Biomicrofluidics 2012, 6, 024129:1-024129:11.

16. Uhlig, K.; Wischerhoff, E.; Lutz, J.-F.; Laschewsky, A.; Jaeger, M.S.; Lankenau, A.; Duschl, C. Monitoring cell detachment on PEG-based thermoresponsive surfaces using TIRF microscopy. Soft Matter 2010, 6, 4262-4267.

17. Lutz, J.-F.; Weichenhan, K.; Akdemir, Ö.; Hoth, A. About the Phase Transitions in Aqueous Solutions of Thermoresponsive Copolymers and Hydrogels Based on 2-(2-methoxyethoxy)ethyl Methacrylate and Oligo(ethylene glycol) Methacrylate. Macromolecules 2007, 40, 2503-2508.

18. Edwards, E.W.; Chanana, M.; Wang, D. Capping Gold Nanoparticles with Stimuli-Responsive Polymers to Cross Water-Oil Interfaces: In-Depth Insight to the Trans-Interfacial Activity of Nanoparticles. J. Phys. Chem. C 2008, 112, 15207-15219.

19. Lutz, J.-F.; Pfeifer, S.; Zarafshani, Z. In Situ Functionalization of Thermoresponsive Polymeric Micelles using the "Click" Cycloaddition of Azides and Alkynes. QSAR Comb. Sci. 2007, 26, 1151-1158.

20. Kessel, S.; Schmidt, S.; Müller, R.; Wischerhoff, E.; Laschewsky, A.; Lutz, J.-F.; Uhlig, K.; Lankenau, A.; Duschl, C.; Fery, A. Thermoresponsive PEG-Based Polymer Layers: Surface Characterization with AFM Force Measurements. Langmuir 2010, 26, 3462-3467.

21. Okano, T.; Yamada, N.; Okuhara, M.; Sakai, H.; Sakurai, Y. Mechanism of cell detachment from temperature-modulated, hydrophilic-hydrophobic polymer surfaces. Biomaterials 1995, 16, 297-303. 
22. Yamato, M.; Okuhara, M.; Karikusa, F.; Kikuchi, A.; Sakurai, Y.; Okano, T. Signal transduction and cytoskeletal reorganization are required for cell detachment from cell culture surfaces grafted with a temperature-responsive polymer. J. Biomed. Mater. Res. 1999, 44, 44-52.

23. Yamato, M.; Konno, C.; Kushida, A.; Hirose, M.; Utsumi, M.; Kikuchi, A.; Okano, T. Release of adsorbed fibronectin from temperature-responsive culture surfaces requires cellular activity. Biomaterials 2000, 21, 981-986.

24. Zimmermann, H.; Richter, E.; Reichle, C.; Westphal, I.; Geggier, P.; Rehn, U.; Rogaschewski, S.; Bleiß, W.; Fuhr, G.R. Mammalian cell traces-Morphology, molecular composition, artificial guidance and biotechnological relevance as a new type of bionanotube. Appl. Phys. A 2001, 73, 11-26.

25. Rigort, A.; Grünewald, J.; Herzog, V.; Kirfel, G. Release of integrin macroaggregates as a mechanism of rear detachment during keratinocyte migration. Eur. J. Cell Biol. 2004, 83, $725-733$.

26. Ebara, M.; Yamato, M.; Aoyagi, T.; Kikuchi, A.; Sakai, K.; Okano, T. Temperature-Responsive Cell Culture Surfaces Enable "On-Off" Affinity Control between Cell Integrins and RGDS Ligands. Biomacromolecules 2004, 5, 505-510.

(C) 2014 by the authors; licensee MDPI, Basel, Switzerland. This article is an open access article distributed under the terms and conditions of the Creative Commons Attribution license (http://creativecommons.org/licenses/by/3.0/). 